\title{
EXPERIMENTAL STUDY ON THE RIVETED JOINTS IN GLASS FIBRE REINFORCED PLASTICS (GFRP)
}

\begin{abstract}
The aim of the paper is to validate the use of measurement methods in the study of GFRP joints. A number of tests were carried out by means of a tensile machine. The studies were concerned with rivet connection of composite materials. One performed two series of tests for two different forces and two fibre orientations. Using Finite Element Method (FEM) and Digital Image Correlation (DIC), strain maps in the test samples were defined. The results obtained with both methods were analysed and compared. The destructive force was analysed and, with the use of a strain gauge, the clamping force in a plane parallel to the annihilated sample was estimated. Destruction processes were evaluated and models of destruction were made for this type of materials taking into account their connections, such as riveting.
\end{abstract}

\section{Introduction}

For the last few years, the application of composite materials has increased in different areas of science and technology due to their unique properties. Glass Fibre Reinforced Plastics (GFRPs) are the most commonly used in mechanical parts in pieces and structures in industry [1]. The main reasons for such a high demand in fibreglass composites are their prominent specific stiffness and strength properties, which lead to substantial weight decrease [2].

One of the most difficult issues concerning mechanically-fastened joints in fibreglass materials is that the well-set design procedures for steel connections, developed based on years of tests using homogeneous and isotropic materials, need changing in order to accommodate the anisotropic and non-homogeneous directional qualities of composite materials. In addition, composite materials do

\footnotetext{
${ }^{1}$ Warsaw University of Technology, Institute of Aeronautics and Applied Mechanics, Nowowiejska 24,00-661 Warsaw, Poland. Emails: bielawski@meil.pw.edu.pl, mkowalik@meil.pw.edu.pl, ksuprynowicz@meil.pw.edu.pl,wrzadkowski@meil.pw.edu.pl,pyrzan@meil.pw.edu.pl
} 
not exhibit plastic deformation which can reduce local stress concentration. The inherent brittle behaviour of composites causes that the joints and connections are liable to damage prior to ultimate failure as there is no stress redistribution thanks to material plasticity [3]. Fibre composite laminates seem to be better than monolithic metals and other materials, and because of their high strength-toweight and stiffness-to-weight ratios, etc., they are often chosen for manufacturing new products. However, there are certain limitations in composite laminates. For example, the interlaminar strength and overall stretch ratio is not as high as in a monolithic material. Joining technology in composite structures, if we compare it with metal structures, is a far more important subject, because in 60-85 percent of cases damage may appear at the fastening joint. It shows that interference-fit joining can have big influence on the fatigue life of metal structures, so it is one of the most widely-used methods for elongating service life of metal structures [4].

Connections components, made of composites, are frequently encountered in modern structures. This way of connection is not only cheap but also fast and firm. Commonly, there are two types of methods to make joints in composite structures. These are mechanical and adhesively-bonded joints. There are both advantages and disadvantages of using mechanical joints in comparison with adhesively-bonded joints [5] in assembling composite parts. For example, in mechanical joining, rivets or/and bolts through holes are required, which results in concentrations of stress that finally lead to possible failures. The adhesive joints do not need holes and the load is spread over a larger area than that in mechanical joints [6]. Yet, they remain quite vulnerable to the surface treatment, service temperature, humidity, and other environmental conditions. For these and other reasons, they are also difficult to be fixed. The study presented in this paper focuses on GFRP in the context of riveted joints and measurement methods applicable to them. We analyse the impact of the additional active clamping force which arises from the head of rivet and we examine its impact on the destructive force.

Strain distribution was determined with the Digital Image Correlation (DIC) method. DIC results were compared with the analysis performed with Finite Element Method (FEM). According to the test results, one have developed damage models for the material. The research reported in the article refers to similar studies by the authors [7] and other studies [8-10], conducted on the GFRP and Carbon Fibre Reinforced Plastics (CFRP) composites.

\section{Experiment part}

\subsection{The specimen}

The samples used for testing were constructed of one type of fabric. Interglas 92140 fabric was used to build perpendicular and angle-ply samples. The mechanical properties of the materials observed during the experiment are depicted in Table 1 [11]. 
Fibre and laminate mechanical properties according to the experiment

\begin{tabular}{|l|c|c|}
\hline Strength propertis & Designation [titre] & Interglas 92140 \\
\hline Basis weight $\left[\mathrm{g} / \mathrm{m}^{2}\right]$ & $\mathrm{q}_{\mathrm{w}}$ & 390 \\
Fiber thickness [mm] & $\delta^{(1)}$ & 0.5 \\
Tensile strength [MPa] & $\delta^{(2)}$ & 0.36 \\
Compressive strength [MPa] & $\mathrm{R}_{\mathrm{M}+}$ & 345 \\
Young's modulus [GPa] & $\mathrm{R}_{\mathrm{C}+}$ & 218 \\
& $\mathrm{E}_{+}$ & 22.4 \\
Kirchoff's modulus [GPa] & $\mathrm{E}_{\mathrm{X}}$ & 12.1 \\
& $\mathrm{G}_{+}$ & 4.3 \\
Stiffness [km] & $\mathrm{G}_{\mathrm{x}}$ & 8.8 \\
& $\mathrm{k}_{\mathrm{RM}+}$ & 65 \\
& $\mathrm{k}_{\mathrm{RC}+}$ & 41 \\
& $\mathrm{k}_{\mathrm{E}+}$ & 4219 \\
& $\mathrm{k}_{\mathrm{Ex}}$ & 1143 \\
& $\mathrm{k}_{\mathrm{G}+}$ & 400 \\
Fiber density [g/cm ${ }^{3}$ ] & $\mathrm{k}_{\mathrm{Gx}}$ & 829 \\
& & 2.55 \\
\hline
\end{tabular}

The composite laminates were fabricated by the hand lay-up technique in an autoclave according to the manufacturer's recommended curing procedure. The construction of composite sample was of three-layers type. Each type of sample fibre orientation is represented in a series of research results (Table 2).

Table 2.

Forming composite probe

\begin{tabular}{|c|c|c|c|}
\hline Fiberglass name & Series & Orientation icon & Laminate code \\
\hline \multirow{2}{*}{ Interglas 92140 } & I & $\searrow$ & {$\left[-45_{2} / 45\right]_{S}$} \\
\cline { 2 - 4 } & II & $\uparrow$ & {$\left[0_{2} / 90\right]_{S}$} \\
\hline
\end{tabular}

The composite was subjected to a curing process at ambient temperature under a vacuum clamp for 6 hours, and then for further 14 hours without a vacuum. This action was performed in an identical manner for both types of fabrics. Laminating was made at $24^{\circ} \mathrm{C}$ and humidity of $59 \%$. In the process of lamination, the adhesive epoxy resin [12] was a combination of Epidian 53 with Z-1 hardener in a 10:1 ratio. The film layer was removed after the lamination time (about 50 minutes). The samples were cut in order to give them the assumed shapes. The optical quality test was conducted. Selected composite specimens were subjected to a heating process in order to improve their mechanical properties, and then the aftercure process continued lasting 8 hours at $60^{\circ} \mathrm{C}$ according to the manufacturer's requirement.

The composite specimen is presented in Fig. 1. It had dimensions of $100 \times 100$ $\mathrm{mm}$ and thickness of approximately $1 \mathrm{~mm}$. 


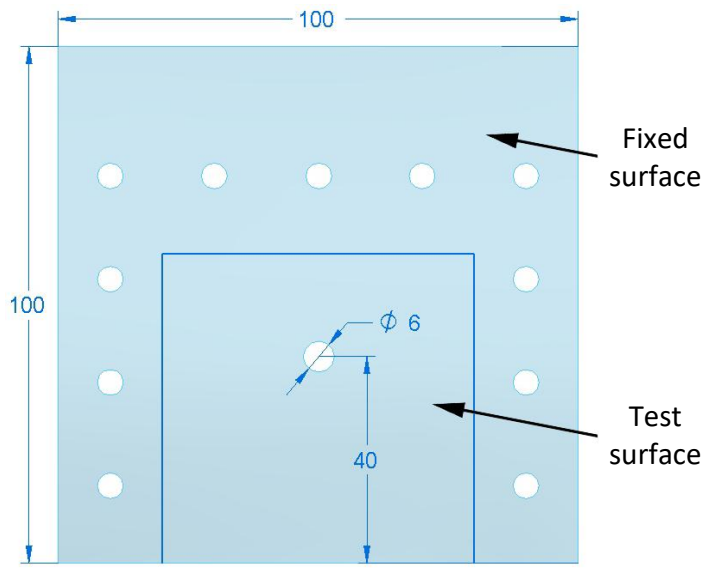

Fig. 1. Geometry of the specimen

A hole of diameter $\varnothing 6 \mathrm{~mm}$ was drilled in the middle of the test surface and a metal pin was placed there. At the edges of the sample, 11 holes were made. The holes were drilled with drill bits for composite treatment [13]. The test area was painted with white matt lacquer Standox, and black markers were applied to facilitate to carry out the DIC method. The test area of the samples had dimensions of $60 \times 60 \mathrm{~mm}$ and the specimen were placed in a metal frame (Fig. 2).

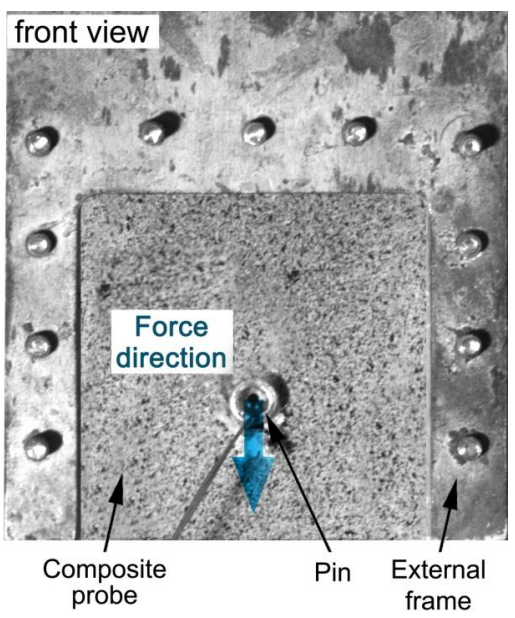

a) front view

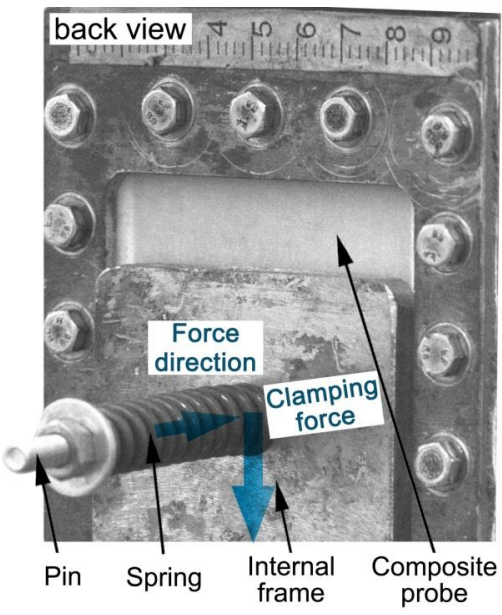

b) back view

Fig. 2. Test system with the pin and the spring

The specimen was fixed in a frame with a screw connection which was made of screws with nominal thread pitch M5. The screws were powertight with constant torque and they provided a uniform clamping force over the whole contact area of the frame with the sample. 
During the test, a special pin was used. This was an Allen's screw M6 of total length of $90 \mathrm{~mm}$. It was made of metric thread of total length of $60 \mathrm{~mm}$. It was used to compress the spring and produce appropriate fixed clamping force. The clamping force was induced by compression of the spring with a screw on an appropriate fixed length. A strain gauge was glued on the pin (Fig. 3).

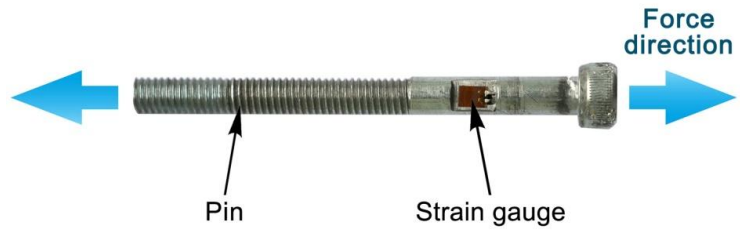

Fig. 3. Pin with foil strain gauge

The strain gauge was mounted on a flat surface at a distance of $65 \mathrm{~mm}$ from the end of the pin between its threaded part and the head. In the midst of the pin, there was a $\emptyset 1 \mathrm{~mm}$ hole through which the cables were run. The properties of the sensor are summarised in Table 3.

Table 3 .

TENMEX TF-1/120 strain gauge properties

\begin{tabular}{|l|l|}
\hline \multicolumn{2}{|c|}{ Basic properties } \\
\hline Width & $2.3 \mathrm{~mm}$ \\
Length & $3.0 \mathrm{~mm}$ \\
\hline \multicolumn{2}{|c|}{ Measurement grid } \\
\hline Active length of path & $1.0 \mathrm{~mm}$ \\
\hline
\end{tabular}

\subsection{Experiment performance}

The aim of the experiment was to perform a series of tests on the tensile machine INSTRON 8516 with a metal pin. The samples were extended, at a speed of $0.05 \mathrm{~mm} / \mathrm{s}$, at a distance of up to $15 \mathrm{~mm}$. During the tensile test, one registered displacement of the connection and the pull force. The clamping force values were also measured using a strain gauge. Both forces were recorded as a function of the tensile machine's traverse displacement.

In the first stage, the samples with an angle-ply of the fibbers (I series) and the second part samples with simple fibber orientation (II series) were tested. There were 16 composite test pieces altogether. One applied there two different initial clamping forces $(400 \mathrm{~N}$ and $750 \mathrm{~N}$ ) produced by a helical spring with linear characteristics and stiffness coefficient equal to $0.6 \mathrm{kN} / \mathrm{mm}$. The clamping force applied during the tests was spread on the surface of the screw head of approximately $35 \mathrm{~mm}^{2}$ (appropriately for I series about $10 \mathrm{MPa}$, and for II series $20 \mathrm{MPa}$ ). 


\section{Analysis of forces}

Figs 4 and 5 show the average courses of the pull force - black line - as a function of the displacement for two different initial clamping forces ( $400 \mathrm{~N}$ and $750 \mathrm{~N}$ ). The increment clamping force vs. pin displacement is drawn as the blue line. The line shows the average value taken for the five samples tested.

All the courses (the pull force vs. displacement) can be divided into three parts:

- fast linear growth of the force,

- slower growth to maximum,

- quasi-stabile course approx. at a half of maximum value.

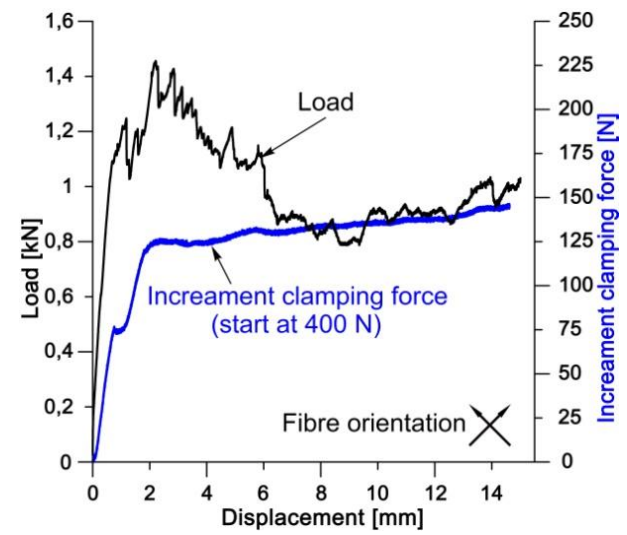

(a)

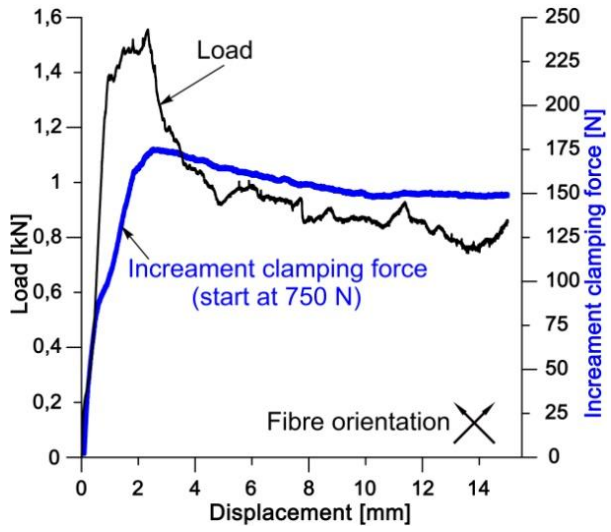

(b)

Fig. 4. Pull force (load) and increment clamping force vs. pin displacement for I series "X":

a) 1-series, b) 2-series

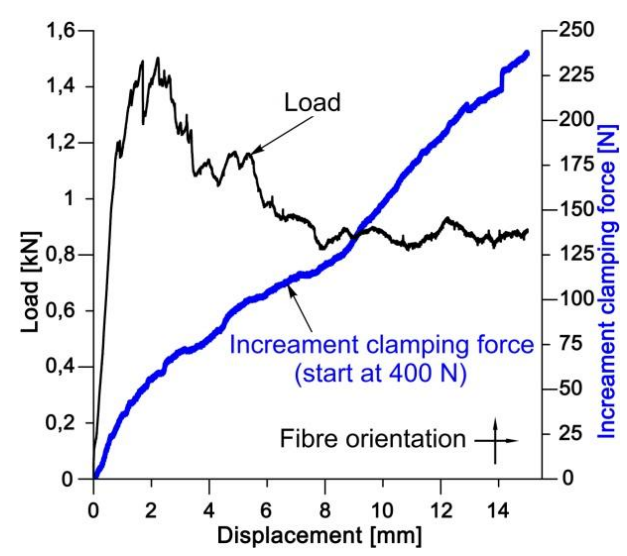

(a)

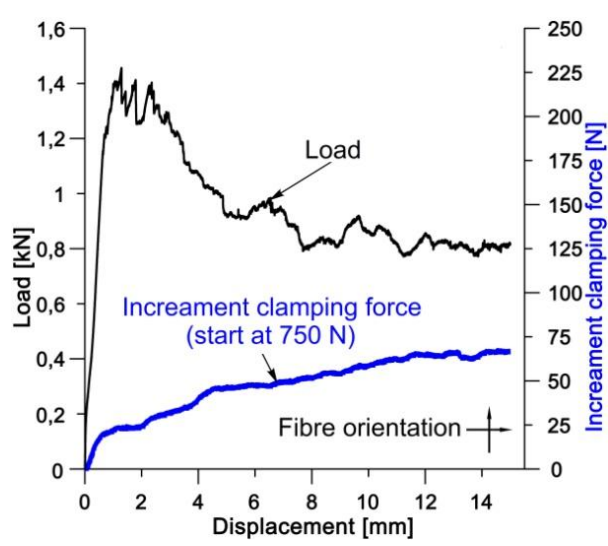

(b)

Fig. 5. Pull force (load) and increment clamping force vs. pin displacement for II series "+": a) 1-series, b) 2-series 
By analysing the black plot one can see characteristic lines with inflection in the first part of it at a value of approx. $0.2 \mathrm{kN}$. The reason is probably the destruction of individual fibres protruding from the hole. Next, the pull force grows to maximum. Linear part of this increase ends at about $0.5-0.7 \mathrm{~mm}$ and the maximal value is achieved for approx. $1.8-2.5 \mathrm{~mm}$. In this range, the connection is well-working and, despite the destruction of the displacement, still carries the load. Then, the slow decline in the value of the force and its stabilisation at displacement of about $7 \mathrm{~mm}$ is visible. The stabilised force is about twice smaller than the maximal value. The force curve is not smooth, due to fact that the material is not homogeneous and the destruction process consists in destroying individual fibers and their bundles.

Blue plots in Fig. 4 from I series show increment of clamping force versus pin displacement. One can see rapid build-up of forces. In the middle of this course, there is a specific breakdown of the line, which corresponds to the values of the destruction of the composite sample. Then, the plots' character changes. For I-1 series there is a slight increase in the increment clamping force (Fig. 4a), while for the series I-2 there is a slight decrease in the increment clamping force (Fig. 4b). The characteristic break in the curve occurs at the offset value of approx. $2 \mathrm{~mm}$. The reason for this effect is that a cycle of destruction of the sample starts. The difference between the values of the inflection point is about $10 \%$.

The diagrams of the II series have a different character. For the simple fibres, the chart clamping force originating from the translation of the pin constantly grows. For a smaller clamping force it is quasi-linear and increases up to $250 \mathrm{~N}$ (see Fig. 5a) without stabilisation. It is very likely that further studies, carried out over longer pin distances, might show its characteristics. This will be the subject of subsequent studies of this type.

Fig. $5 \mathrm{~b}$ shows the graph for a higher clamping force. The nature of the curve is similar to the chart for the series. Inflection of the curve is visible. Inflection point corresponds to the displacement values at which the destruction of the samples has occurred. The rest of the curve is increasing almost linearly until the stabilisation occurs. From the distance of $11 \mathrm{~mm}$, the curve stabilises at a constant level. It is interesting that the value of the maximum clamping force, compared with less force for the series, is much lower and amounts to approx. $30 \%$ of its maximum value.

The minimum and maximum forces, as well as the differences between them, are summarised in Table 4.

Table 4.

Maximum and minimum forces value depending on the series

\begin{tabular}{|c|c|c|c|c|}
\hline \multirow{2}{*}{ Series } & \multicolumn{3}{|c|}{ Pull force [kN] } & $\begin{array}{c}\text { Increment clamping } \\
\text { force [N] }\end{array}$ \\
\cline { 2 - 5 } & Max value & Min value & Difference & Max value \\
\hline I - 1 & 1.45 & 0.78 & 0.67 & 148 \\
I-2 & 1.55 & 0.74 & 0.81 & 178 \\
II - & 1.50 & 0.82 & 0.68 & 240 \\
II -2 & 1.46 & 0.77 & 0.69 & 68 \\
\hline
\end{tabular}




\section{Failure analysis}

Four common failure modes are often described in the literature: bearing, shear-out, net-tension and cleavage [14-18]. According to the experiment results, one model of the damage was identified and is presented in Fig. 6. For all the tested samples, there may be observed a bearing type of damage. It should be noticed that the damage model does not depend on the clamping force value. The additional clamping force affects only the area of the damage.

For the series I (see Fig. 6a and 6b), the extent of the damage is similar despite the different clamping forces. The side walls are approximately straight and the cutout material can be observed. There are only occasional fibres that split off from

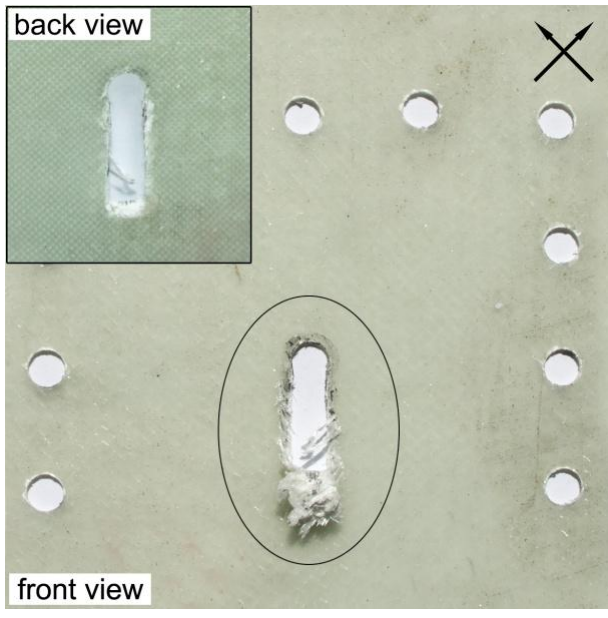

(a)

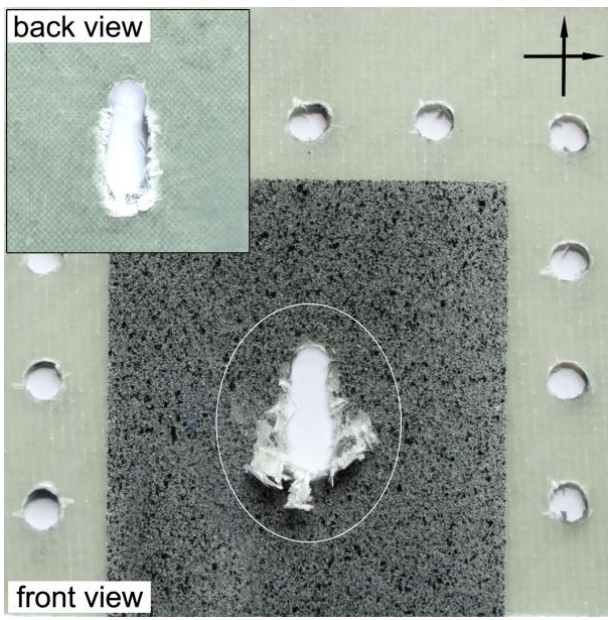

(c)

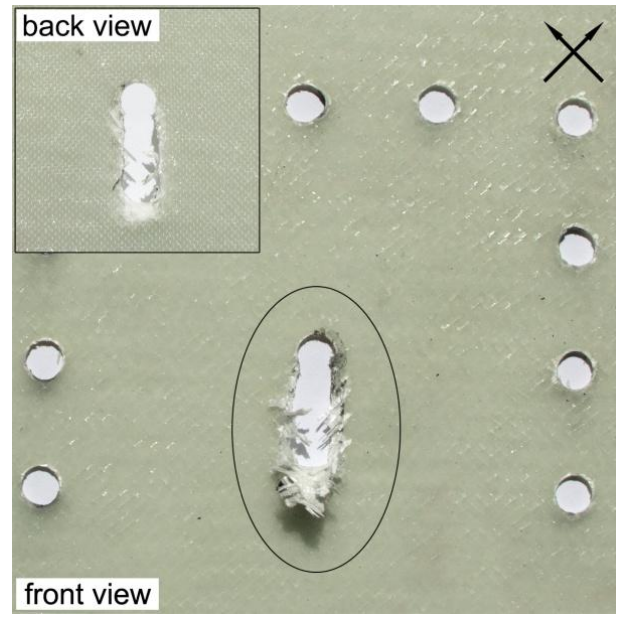

(b)

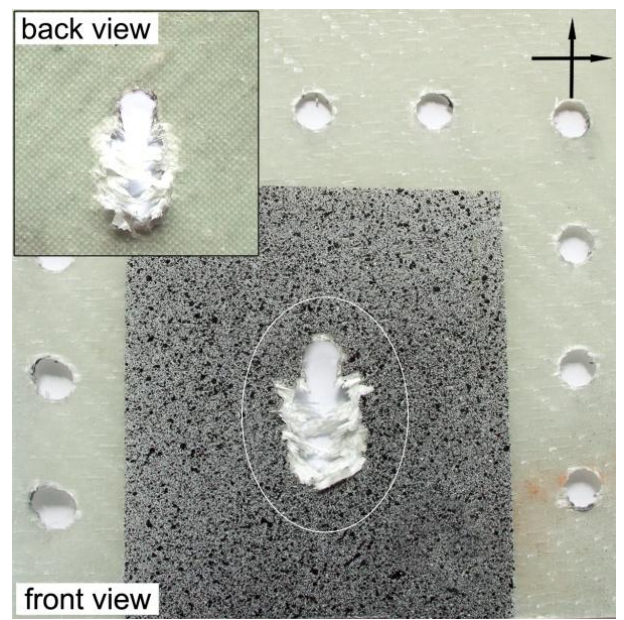

(d)

Fig. 6. Damage of specimens for series: a) I-1 series, b) I-2 series, c) II-1 series, d) II-2 series 
the matrix. On the view of the front directly before the pin, the accumulation of damaged material is visible. On the back view, separated fibres are almost invisible.

For the series II (see Fig. 6c and 6d), the area of the damage depends on the clamping force. For II-2 series (see Fig. 6d), there can be seen a relatively large area of separation of individual fibres from the matrix. They are visible both in front and back views. For Series II-1, Fig. 6c shows a smaller area of destruction, but the accumulation of damaged material is increased in front of the pin and on the sides.

\section{The analysis of strains}

Displacement and strain distributions on the specimens' surface were measured using the Digital Image Correlation (DIC) based algorithm [2, 3, 6]. The algorithm adapted for planar strain cases was used. The set-up consisted of a digital DSLR camera with lens' optical axis perpendicular to the sample's surface and of two DC-powered light emitting diode clusters used as a light source. During the test, photographs were taken in 1 second intervals, what corresponds to $0.05 \mathrm{~mm}$ of traverse moving. Samples were painted using white matte acrylic lacquer. To create a random pattern of markers on samples' surface, a black acrylic paint was used. A camera sensor with Bayer array filter was used and the photographs had to be converted from colour to monochrome by using green pixels only. Such a method reduces the error caused by chromatic aberration.

The used algorithm detects markers in a desired size range, shape and contrast. Positions of the markers are tracked with sub-pixel resolution using Pearson correlation coefficient calculated for brightness of pixels in a specified radius around each detected marker in every two consecutive photographs. The algorithm selects position with the highest correlation coefficient. If the correlation coefficient is lower than the assumed threshold, the marker is rejected for this and the following photographs. Using valid marker positions, a triangular mesh is built for each frame using Delaunay triangulation. Each mesh node is placed on a marker. Displacements inside triangles are interpolated linearly from displacement of triangle vertices. The triangles for which the edge deformation exceed an assumed threshold are removed to detect fracture and destruction zone. Each mesh represents mapping from the initial state to the deformed state represented on respective photograph. The initial state image can then be deformed using mesh-based mapping function to approximate the shape of the sample with an applied load. Displacements of each node are then optimised to achieve highest Pearson correlation coefficient between brightness distributions in the area around the node on the deformed initial image and the analysed one. This approach allows for accurate measurements of large deformations and strain values in proximity of fractures and material destruction zones. Strain distribution is derived from this mapping using finite differences and filtered using Gaussian kernel to remove noise. 
The strains in vertical direction are presented in Fig. 7. All the maps have been generated in the same phase of tensile test, for displacement of about $2 \mathrm{~mm}$. The maximum values of compressive strain are $0.2 \%$, while the minimum values of tensile strain are $-0.2 \%$ (the difference equal to $0.4 \%$ ). For all specimens, as it was expected, the minimum value of strains (maximal compression) appeared under the pin. The course of isolines shows a considerable strain concentration in the pin-specimen contact zone.

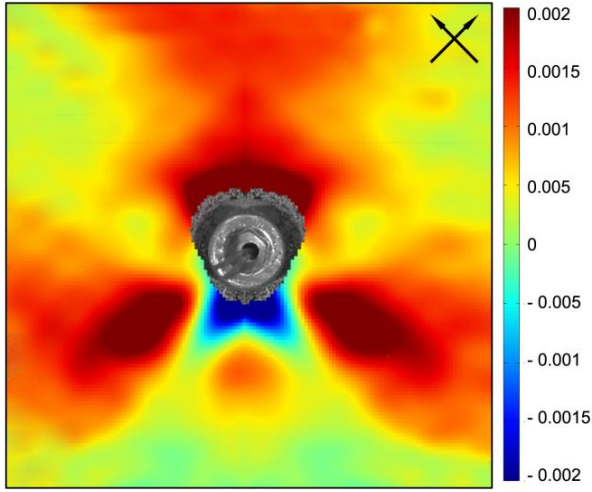

(a)

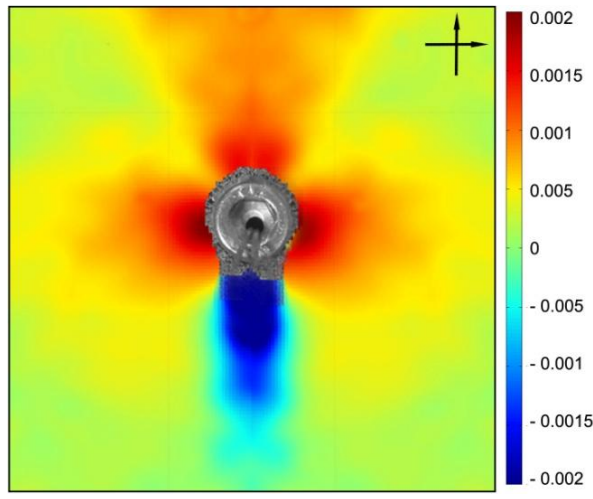

(c)

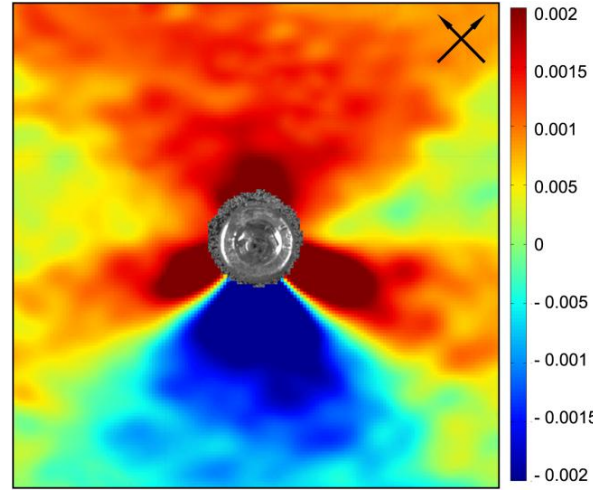

(b)

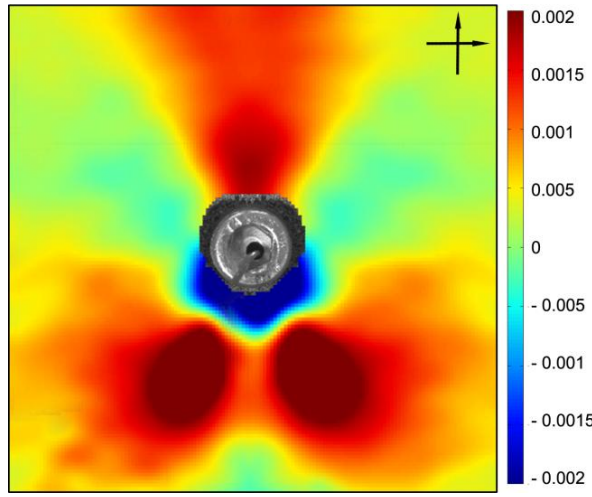

(d)

Fig. 7. The distribution of strains in the vertical direction from DIC: a) I-1 series, b) I-2 series,

c) II-1 series, d) II-2 series

For I series, the vertical strain distribution for the two forces is similar. For I-2 series, the area of maximal compression directly under the pin is much larger.

For II series (Fig. 7c and 7d), strain distribution in the vertical plane depends on the clamping force. The area of minimum value of strains for series II-1 is elongated and extends in a vertical plane, in contrast with the series of II-2. The areas of strong tensile strains appear in different places.

For the Finite Element Method study, the ANSYS 14.5 software has been used. The FEM model is presented in Fig. 8. 


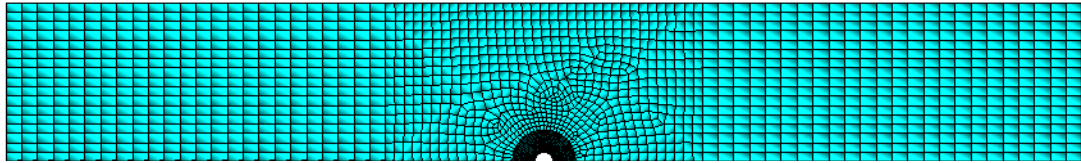

(a)

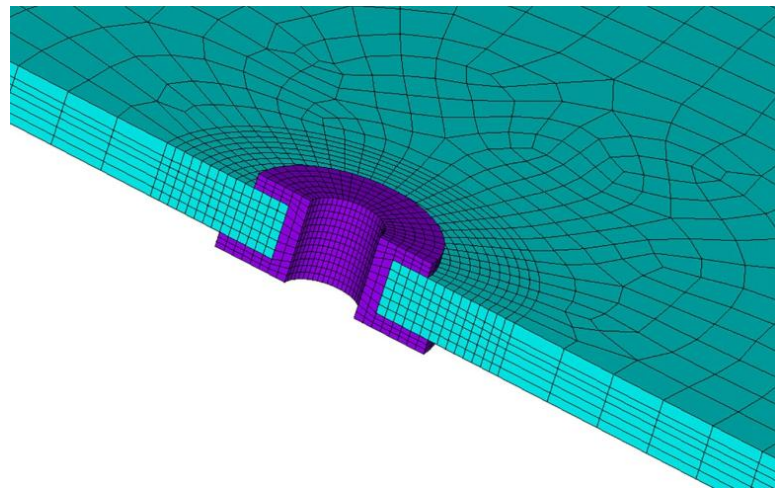

(b)

Fig. 8. The FEM model: a) the whole body; b) magnification of the region near the rivet

FE model has been built using 8-node solid elements (SOLID185), where every node has 3 degrees of freedom. Element size varies from 0.4 to $3 \mathrm{~mm}$. Symmetry condition was also used, so the total number of elements was about 14500. The performed analysis was structural-static with active option of nonlinear effects. A linear material model with a constant stiffness has been used.

Strain distribution from FE method in the vertical plane for the selected cases are presented in Fig. 9. The results were compared and validated with the results of DIC method. Because the model did not implement material damage, there was a slight difference between the results of the two methods.

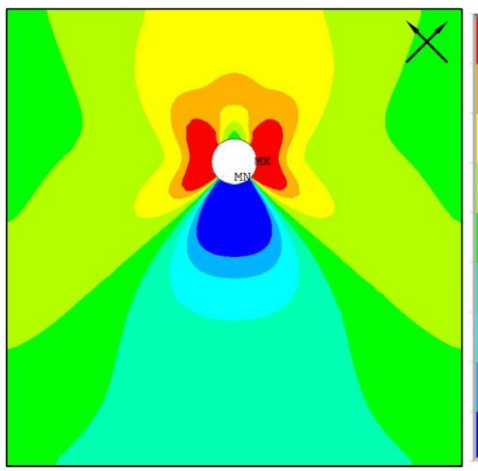

(a)

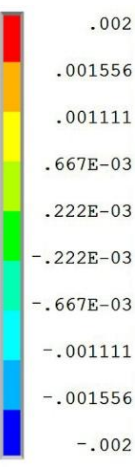

$-.002$

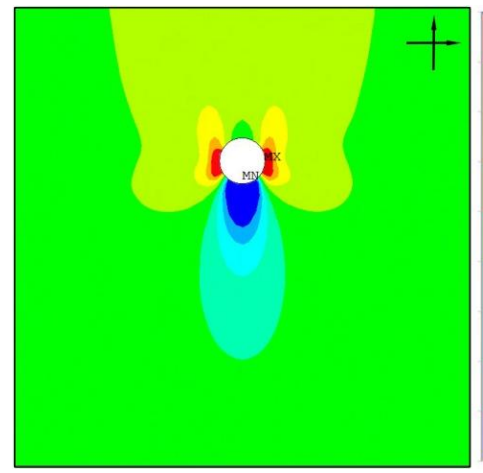

(b)

Fig. 9. The distribution of strains in the vertical direction from FEM: a) I-2-series, b) II-1-series 


\section{Conclusions}

The study confirmed the applicability of riveted joints in GFRP composite materials. Additional use of methods such as DIC and FEM can be very useful in modelling and analysis of this type of connection. The performed studies allow us to draw several conclusions:

1. After the initial stretch of destruction, for the pin displacement of about $2 \mathrm{~mm}$ ( $1 / 3$ of its diameter), the pull force reaches its maximum. For the pin distance equal to about the pin diameter, the destructive force stabilises at a constant value. This value is approximately equal to a half of its maximum. On the basis of the nature of the first stage of rapid growth, one can determine the stiffness modulus of the connection.

2. A distinct relationship between the destructive force and clamping force is observed, especially in the area of the destruction of the material. For the angle-ply fibres orientation, the peak force (for the displacement of about $2 \mathrm{~mm}$ ) corresponds to the inflexion point of the clamping force curve. From this point, the clamping force value decreases rapidly and stabilizes at a constant level. For the simple fibres orientation, the value of the clamping force increases during traverse moving. However, there are noticeable differences between both initial values of the force.

3. In the test samples, we identified one of the four possible types of damage in composites - the bearing type. The clamping force value does not change the type of failure, only its form. The damage is local, which shows that rivets can be used to join these types of composites.

4. The DIC method, with a suitable algorithm, allowed for the determination of the deformation in the vertical plane - according to the active force. FEM method was used, and was verified by DIC method. It did not include the destruction stage, which also had an impact on the results. Numerical calculations are helpful for understanding the phenomena occurring in the composite materials and for modelling strains, displacements and other quantities important for the designers.

Manuscript received by Editorial Board, October 12, 2016; final version, June 09, 2017.

\section{References}

[1] J.P. Davim, P. Reis, and C.C. Antonio. Experimental study of drilling glass fiber reinforced plastics (GFRP) manufactured by hand lay-up. Composites Science and Technology, 64(2):289297, 2004. doi: 10.1016/S0266-3538(03)00253-7.

[2] A. Ataş and C. Soutis. Subcritical damage mechanisms of bolted joints in CFRP composite laminates. Composites Part B: Engineering, 54:20-27, 2013. doi: 10.1016/j.compositesb.2013.04.071. 
[3] A.M. Girão Coelho and J.T. Mottram. A review of the behaviour and analysis of bolted connections and joints in pultruded fibre reinforced polymers. Materials \& Design, 74:86-107, 2015. doi: 10.1016/j.matdes.2015.02.011.

[4] Z. Cao and M. Cardew-Hall. Interference-fit riveting technique in fiber composite laminates. Aerospace Science and Technology, 10(4):327-330, 2006. doi: 10.1016/j.ast.2005.11.003.

[5] M. Kłonica, J. Kuczmaszewski, M.P. Kwiatkowski, and J. Ozonek. Polyamide 6 surface layer following ozone treatment. International Journal of Adhesion and Adhesives, 64:179-187, 2016. doi: 10.1016/j.jjadhadh.2015.10.017.

[6] R.F. Gibson. Principles of composite material mechanics. CRC Press, 4 edition, 2016.

[7] R. Bielawski, M. Kowalik, K. Suprynowicz, and P. Pyrzanowski. Possibility of usage of aluminium rivet nuts connections in composite materials. In Solid State Phenomena, volume 240, pages 137-142. Trans Tech Publications, 2016. doi: 10.4028/www.scientific.net/SSP.240.137.

[8] L. Blaga, J.F. Dos Santos, R. Bancila, and S.T. Amancio-Filho. Friction Riveting (FricRiveting) as a new joining technique in GFRP lightweight bridge construction. Construction and Building Materials, 80:167-179, 2015. doi: 10.1016/j.conbuildmat.2015.01.001.

[9] N. Chowdhury, W.K. Chiu, J. Wang, and P. Chang. Static and fatigue testing thin riveted, bonded and hybrid carbon fiber double lap joints used in aircraft structures. Composite Structures, 121:315-323, 2015. doi: 10.1016/j.compstruct.2014.11.004.

[10] J.-H. Yun, J.-H. Choi, and J.-H. Kweon. A study on the strength improvement of the multi-bolted joint. Composite Structures, 108:409-416, 2014. doi: 10.1016/j.compstruct.2013.09.047.

[11] M. Rodzewicz. An investigation into the strength and fatigue properties of a high-loaded aeronautical composite structures. In Proceedings of the Eight International Seminar Resent Research and Design Progress in Aeronautical Engineering and its Influence on Education, Brno, Czech Republic, 2008.

[12] K. Palanikumar. Experimental investigation and optimisation in drilling of GFRP composites. Measurement, 44(10):2138-2148, 2011. doi: 10.1016/j.measurement.2011.07.023.

[13] C. Atas. Bearing strength of pinned joints in woven fabric composites with small weaving angles. Composite structures, 88(1):40-45, 2009. doi: 10.1016/j.compstruct.2008.04.002.

[14] J.H. Deng, C. Tang, M.W. Fu, and Y.R. Zhan. Effect of discharge voltage on the deformation of Ti Grade 1 rivet in electromagnetic riveting. Materials Science and Engineering: A, 591:26-32, 2014. doi: 10.1016/j.msea.2013.10.084.

[15] J. Zhang, D. Qi, L. Zhou, L. Zhao, and N. Hu. A progressive failure analysis model for composite structures in hygrothermal environments. Composite Structures, 133:331-342, 2015. doi: 10.1016/j.compstruct.2015.07.063.

[16] B. Koohbor, S. Mallon, A. Kidane, and M.A. Sutton. A DIC-based study of in-plane mechanical response and fracture of orthotropic carbon fiber reinforced composite. Composites Part B: Engineering, 66:388-399, 2014. doi: 10.1016/j.compositesb.2014.05.022.

[17] M.A. Sutton, J.J. Orteu, and H. Schreier. Image correlation for shape, motion and deformation measurements: basic concepts, theory and applications. Springer Science \& Business Media, 2009.

[18] W. Zhiqiang, F. Fengzhou, L. Bing, and W. Zhiyong. An experimental method for eliminating effect of rigid out-of-plane motion on 2D-DIC. Optics and Lasers in Engineering, 73:137-142, 2015. doi: 10.1016/j.optlaseng.2015.04.015. 